\title{
Evaluation of Developed Low-Grade Reservoir by Cash Flow Economic Evaluation Method
}

\author{
Liming Liu ${ }^{1}$, Youming Xiong ${ }^{1}$, Songlin Zhang ${ }^{2,3}$, Lixue Chen ${ }^{2}$, Haohan Liu ${ }^{2,3}$ \\ ${ }^{1}$ School of Petroleum Engineering, Southwest Petroleum University, Chengdu, China \\ ${ }^{2}$ School of Computer Science, Southwest Petroleum University, Chengdu, China \\ ${ }^{3}$ Department of Computer Engineering, Sichuan College of Architectural Technology, Deyang, China \\ Email: liuliming_swpu@163.com, songlin_zhang@yeah.net
}

Received March $5^{\text {th }}$, 2013; revised April $6^{\text {th }}$, 2013; accepted April 14 ${ }^{\text {th }}, 2013$

\begin{abstract}
Copyright (c) 2013 Liming Liu et al. This is an open access article distributed under the Creative Commons Attribution License, which permits unrestricted use, distribution, and reproduction in any medium, provided the original work is properly cited.
\end{abstract}

\begin{abstract}
There is no united method to evaluate developed low-grade reservoir. Cash flow economic evaluation method is widely used in China and other countries. Cash flow method contains three different economic evaluation methods, they are VP, IRR and investment recovery period methods. In this paper, we evaluate a developed low-permeability sandstone reservoir and a developed middle-high permeability complex fault block sandstone reservoir with the cash flow economic evaluation method. We get the evaluation standard charts of the developed low grade big reservior, developed fault block reservior with middle-high permeability, developed fault block reservior with low permeability and heavy oil thermal recovery reservior. This new cash flow method lays theoretical foundations for evaluation of developed low-grade reservoir and other kinds of reservoirs.
\end{abstract}

Keywords: Cash Flow; Developed; Low-Grade Reservoir; NPV; IRR; Investment Recovery Period

\section{Introduction}

It is difficult to forecast some parameters based on the cash flow economic method without proper mathematical models. In China, many related experts proposed some methods, such as minimum economic reserve method (Li \& Luo, 1999), million ton capacity investment method ( $\mathrm{Li} \& \mathrm{Wu}, 2006$ ) and movable oil price method (Zhong \& Ye, 2009) to facilitate the operation. For example, the minimum economic reserve method is to use the physical properties of oil reservoirs, such as permeability and oil viscosity, reservoir depth, reserves abundance and possible economical factors to model related mathematical models and to calculate the minimum economical reserve. If the evaluation reserve is larger than the minimum economical re- serve, we can draw a conclusion: There is no value for devel- opment of this kind of reserve. The geological institute of Shengli oilfield proposed the movable oil price method after years of practical experience (Chen \& Tian, 2009; Chen, Hu, \& Wang, 2011). This method is based on the theory that the oil price in development project can not be the present real oil price. This method is to determine a decision-making oil price according to the trend of the international oil price and other factors. For example, the decision-making oil price is $35 \$ / b b l$ before Chinese fifteen policy, the decision-making oil price is $18 \$ / \mathrm{bbl}$ during the Chinese fifteen policy. If the profit rate of investment is less than 0.12 , then we think this reserve is im- proper for development. Million ton capacity investment me- thod is similar to the movable oil price method. It is to deter- mine the investment per million ton capacity according to the plans design, indices forecast and cost and investment forecast. If the investment is larger than the inner ruled investment, then we think this reserve is improper for development. Besides, some exports think that it is more feasible for margin reserve evaluation by combing the evaluation foundation, evaluation unit, evaluation parameter and evaluation method (Zhang \& Xie, 1999; Zhao \& Yu, 2011; Guo, 2011; Luo \& He, 2012). Here, we will introduce the cash flow economical method with three kind of mathematical models to evaluate developed low-grade reservoir and other kinds of reservoir

\section{Cash Flow Economical Method}

Cash flow economical method (Xu, Xie, \& Zhang, 2011) is to use the following three mathematical models to evaluate different reserves. The evaluation indices are net present value $(N P V)$, Internal Rate of Return (IRR) and the payback period $\left(T_{p}\right)$.

\section{NPV Method}

$N P V$ is the sum of present value after discount of future net cash flow according to the discount rate. From the point view of investment decisions, it is profitable when the net present value is bigger then 0 . The calculation formula is:

$$
N P V=\sum_{t=1}^{n} \frac{(C I-C O)_{t}}{(1+i)^{t}}
$$

where $N P V$ is net present value;

$C I$ and $C O$ are cash inflows and outflows of certain year;

$i$ is the discount rate;

$t$ is the evaluation year during the evaluation period; 
$n$ is the time period from the evaluation beginning to the evaluation end.

$C I=$ Product operating income recovery of the residual value of fixed assets + recovery of liquidity;

$\mathrm{CO}=$ Capitalization part of investment + development project investment + liquidity + operating cost + sales tax and surcharges.

\section{IRR Method}

$I R R$ is the discount rate during evaluation period when the cumulative discount value of net cash flow is zero. It reflects the capital profitability; it is the major dynamic evaluation indices to reflect the investment profitability. When the $I R R>0$ or $I R R=0$, the related project is feasible. The mathematical model is:

$$
\sum_{t=1}^{n} \frac{(C I-C O)_{t}}{(1+I R R)^{t}}=0
$$

By using Equation (2), we can work out the IRR by using test and interpolation method.

\section{$T_{P}$ Method}

$T_{p}$ is the period of return on investment, it is to say, $T_{p}$ isthe time after recovery of all the initial investment. To the investors $T_{p}$ should be short to avoid the risk of investment. The mathematical model is:

$$
\sum_{t=1}^{T_{p}}(C I-C O)_{t}-C F_{0}=0
$$

where $C F_{0}$ is the initial investment cost;

This model shows: $T_{p}$ is the time that makes the cumulative cash inflows be equal to the cumulative outflows, it reflects the process of return of investment.

\section{Evaluation of Developed Low-Grade Reserve}

Here, we take a certain oilfield in China for example. According to the above-mentioned three mathematical models, we evaluate the developed reserves with different reserve types, different well depth, and different oil price. And we get Figures 1-4, here, $f_{w}$ is maximum water concentration which is allowed.

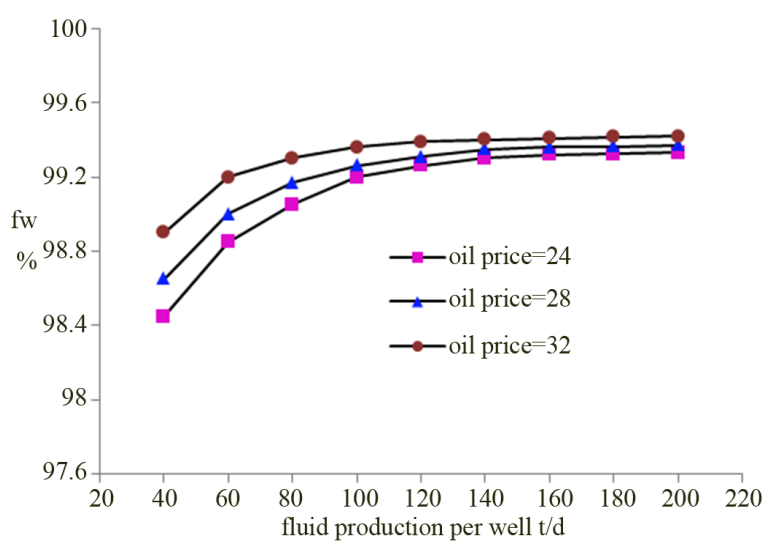

Figure 1.

Caculation chart of developed low grade big reservoir.

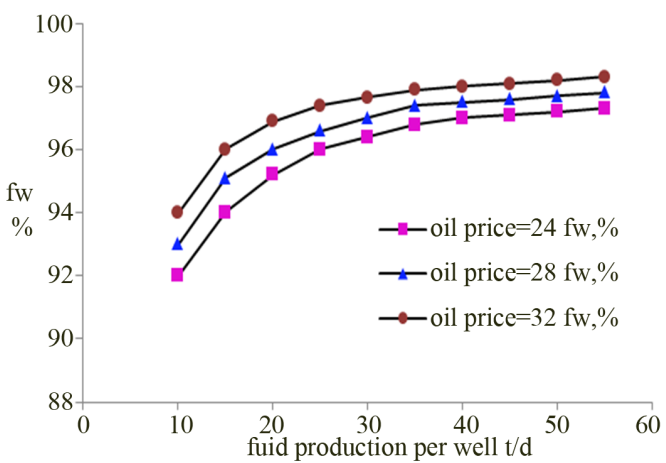

Figure 2.

Caculation chart of developed fault block reservior with middle-high permeability.

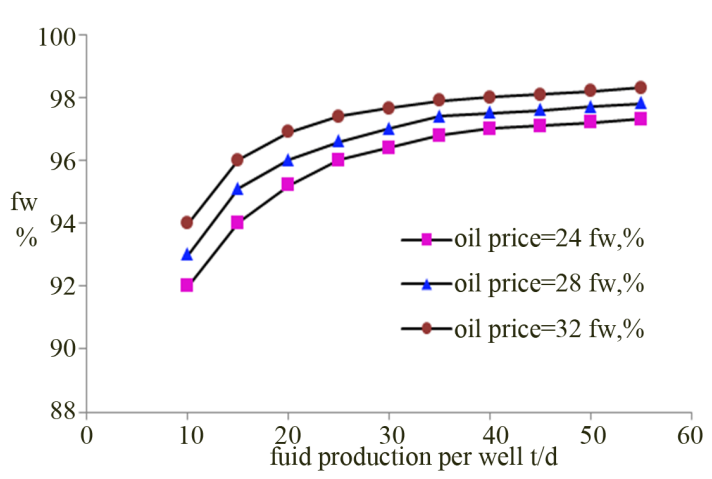

Figure 3.

Caculation chart of developed fault block reservior with low permeability.

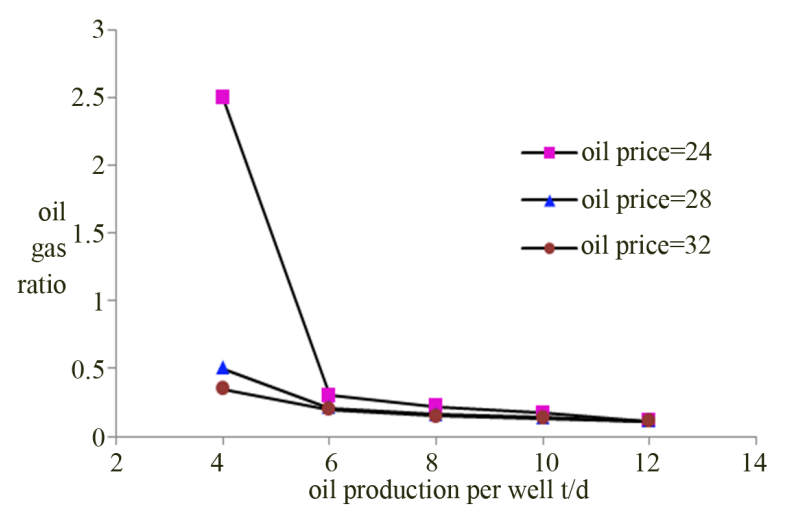

Figure 4.

Caculation chart of heavy oil thermal recovery reservoir.

\section{Conclusion}

By using cash flow economical method, it is, by using three mathematical models with $N P V, I R R, T_{p}$ being the evaluation indices to evaluate the developed low grade big reservior, developed fault block reservior with middle-high permeability, developed fault block reservior with low permeability and heavy oil thermal recovery reservior, we get: Standard plates of developed low grade big reservior, developed fault block reservior with middle-high permeability, developed fault block reservior with low permeability and heavy oil thermal recovery reservior. 


\section{M. LIU ET AL.}

\section{REFERENCES}

Chen, G. C., \& Tian, X. P. (2009). Disteribution of turbidite reservoir and its significance in reserve assessment. Marine Geology Frontiers, 27, 8-13.

Chen, H., Hu, Z. G., \& Wang, Y. C. (2011). Application of material balance equation in evaluation of water drive gas reserve. Nei Jiang Science and Technology, 5, 136-137.

Guo, X. P. (2011). Evaluation of dynamic reserves in Jingbian Gas. Liaoning Chemical Industry, 40, 1101-1106.

Li, H., Meng, X.-J., \& Sun, G.-H. (2000). A study on the evaluation method of the economic recoverable reserves of low permeable. Oil Fields Petroleum Geology \& Oilfield Development in Daqing, 19, 31-33.

Li, J. C., \& Luo, H. L. (1999). A new method of reserve's economic evaluation: Minimum economic reserve method. Tuha Oil \& Gas, 1, 27-29.

Li, X. P., \& Wu, A. P. (2006). Decision-making oil price adaptive to the economical evaluation of oilfield development project. Journal of Oil and Gas Technology, 28, 156-157.

Luo, Y., He, P. et al. (2012) Tang Yun research on the parameters for the development potential evaluation of low permeability reservoir. Reservior Evaluation and Development, 2, 24-27.

Xu, D.-S., Xie, X.-J., \& Zhang, A. (2011). Study on beneficial evaluation and optimal model of developed low-grade reservoir. Journal of Southwest Petroleum University (Science \& Technology Edition), 33, 168-171.

Zhang, W. M., \& Xie, P. H. (1999). Evaluation criterion of marginal reserves and DBD in marginal reserves. Oil \& Gas Geology, 20, 302-304.

Zhao, P. F., \& Yu, J. (2011). Methods for shale gas resources assessment. Marine Geology Frontiers, 27, 57-63.

Zhong, Y. S., \& Ye, Z. J. (2009). Economic assessment of relations between investment in oilfield productivity construction and daily single-well output. Sino-Global Energy, 14, 52-56. 